\title{
Design e Sociedade: Um estudo de caso sobre a parceria do Labsol e a Associação de Artesãos de Pompéia - São Paulo
}

\author{
Design and Society: A case study of the Labsol partnership with the Association of \\ Pompéia Craftsmen - São Paulo
}

JERONYMO, Raul M.; Graduando; Universidade Estadual Paulista "Júlio de Mesquita Filho";

raul.molina.j@gmail.com

FARIA, Luis F. S.; Graduando; Universidade Estadual Paulista "Júlio de Mesquita Filho";

luis_silva.faria@hotmail.com

GOYA, Claudio R.; Doutor; Universidade Estadual Paulista "Júlio de Mesquita Filho";

goyaclaudio@hotmail.com

SOUZA, Juliana S.; Mestre; Universidade Estadual Paulista "Júlio de Mesquita Filho";

soares.s.juliana@gmail.com

\section{Resumo}

O trabalho a seguir relata a parceria entre a Associação de Artesãos de Pompéia e o projeto de extensão universitária Laboratório de Design Solidário. Esta parceria consistiu na criação e elaboração de produtos e utensílios feitos de lona de vinil descartada, na tentativa de gerar um seguimento de artesanato urbano na região. Conceitos como sustentabilidade, eco design e economia solidária basearam a metodologia dos projetos e proporcionaram a concepção de produtos artesanais que complementaram o acervo dos artesãos locais. A parceria também contribuiu para uma melhor divulgação dos produtos regionais, possibilitando participações em eventos como o 13. Colóquio de Moda.

Palavras Chave: produtos de lona; artesanato; processo de criação.

\begin{abstract}
This work presents the partnership between the Association of Pompéia Craftsmen and the university extension project Labsol. The partnership consisted in the products conception made in discarded vinyl canvas, on a try to develop regional urban crafts. Concepts like sustainability, eco design and solidary economy grounded the projects methodology and the conception of crafts products that complemented the local artisan's collection. The partnership also contributed to a better divulgation of the regional products in events like the $13^{\text {th }}$ Colóquio de Moda.
\end{abstract}

Keywords: banner canvas products; crafts; creation process. 


\section{Introdução}

O artigo apresenta o resultado da parceria entre o projeto de extensão universitária intitulado Laboratório de Design Solidário (Labsol), da Faculdade de Arquitetura, Artes e Comunicação (FAAC), Universidade Estadual Paulista "Júlio de Mesquita Filho" (UNESP) e a Associação de Artesãos de Pompéia (AAP), localizada em Pompéia - SP, durante o ano de 2017.

O Labsol possui como principal proposta o desenvolvimento de ações conjuntas entre o design e o artesanato como patrimônio cultural, trabalhando a partir de um tripé constituído pelos conceitos de Sustentabilidade (MANZINI, 2002), Economia Solidária (SINGER, 2002) e Ecodesign (BREZET, 1997), de maneira a atender grupos e comunidades de artesãos, inserindo seus produtos dentro do mercado de maneira mais eficiente. Promove, em parceria com grupos artesãos, projetos e ações que contribuem no processo de desenvolvimento dos artefatos, levando em conta a cultura e comunidade local (GOYA, et. al. 2014).

A AAP, fundada em fevereiro de 2016 e localizada em Pompéia - SP, é composta por artesãos que se reúnem para trocar conhecimento e produzir suas obras no espaço disponibilizado pela prefeitura da cidade Instituto de Desenvolvimento Familiar Chieko Nishimura. A associação tem como objetivo melhorar a convivência, a assistência e o respeito dos artesãos da cidade, além da geração de renda. Grande parte de suas produções são propostas de reutilização de materiais descartados na cidade.

O Instituto de Desenvolvimento Familiar Chieko Nishimura, atuante em programas de educação, capacitação, formação e desenvolvimento especializado em famílias e profissionais, também da cidade de Pompéia, contribui tanto para a disponibilização do espaço para encontros e manufatura dos artesãos, quanto para dar suporte a interessados em participar da associação.

O contato entre o Labsol e a AAP ocorreu por via da Jacto Incorporated, empresa nacional voltada para a produção de máquinas e equipamentos agrícolas. Após a realização de um encontro mediado pela UNESP e pela Jacto Inc., foi assumido um vínculo entre o Labsol e a AAP, propondo novos projetos e auxílio em conjunto.

\section{Caracterizando o Laboratório de Design Solidário}

\subsection{O Labsol}

O Labsol, Laboratório de Design Solidário, é um projeto de extensão vinculado ao Departamento de Design da FAAC, UNESP. A principal missão do Labsol é desenvolver ações em parceria com comunidades e grupos que tenham como base financeira o artesanato, orientando as técnicas e processos produtivos, agregando valor a sua linha de produção através do design e prezando a identidade cultural, patrimônio histórico da comunidade local e sua inserção no mercado. 


\subsection{0 tripé: Sustentabilidade, Ecodesign e Economia Solidária}

A Sustentabilidade faz referência às condições sistêmicas, segundo as quais em nível regional e planetário, as atividades humanas não devem interferir nos ciclos naturais em que se baseia tudo o que a resiliência do planeta permite, e ao mesmo tempo, não devem empobrecer seu capital natural, que será transmitido ás gerações futuras (MANZINI \& VEZZOLI, 2002). Portanto compreende-se por Sustentabilidade a capacidade de utilizar ferramentas e estratégias que conciliem as necessidades de desenvolvimento material e econômico com a preservação do meio ambiente, de forma que a biodiversidade e ecossistemas locais e planetários não sejam comprometidos.

Aliado aos princípios da sustentabilidade, o Ecodesign (BREZET, 1997) tem como principal objetivo desenvolver produtos, sistemas e serviços compatíveis com o uso consciente de recursos não renováveis e que sejam capazes de minimizar o impacto ambiental causado pela sua produção e ciclo de vida.

Complementando essa mesma linha, a Economia Solidária "é uma economia de mercado com base associativista e cooperativista, voltada para a produção, consumo e comercialização de bens e serviços, buscando a valorização do ser humano e não do capital, dentro de um processo de democratização econômica" (SINGER, Paul, 2002). Trata-se de produzir através de práticas econômicas e sociais não competitivas que valorizam a autogestão, a horizontalidade e o cooperativismo, ou seja, um formato organizacional que beneficia todos os seus integrantes, pois não há relações hierárquicas ou exploração de mão de obra, resultando numa igualdade de poder de decisões que reflete no espaço público, pois contribui para a construção de um meio socialmente justo e sustentável.

\section{Desenvolvimento}

Através do contato com Anderson Rolim da Jacto Inc., o projeto de extensão foi informado da parceria entre a área social da empresa em conjunto do Instituto Chieko Nishimura com a AAP e o interesse de desenvolver um vínculo com o Labsol. De acordo com o comunicado, a AAP gostaria que o projeto avaliasse a qualidade de suas produções, de maneira a propor melhorias ou mesmo novos artefatos. Para tanto, foi sugerido que o Labsol realizasse uma viagem à cidade para conhecer a fábrica e a associação, de maneira que realizasse projetos levando em conta as características locais.

\subsection{Produtos da Associação}

Com a realização da viagem em julho de 2017, os integrantes do projeto de extensão tiveram acesso à linha de produção da fábrica e de informações sobre os resíduos gerados pela Jacto Inc. Essa oportunidade permitiu identificar o excesso de materiais inutilizados, como lona de vinil, que é armazenada após apresentações em eventos de máquinas agrícolas. 
Os membros do projeto também tiveram acesso ao Instituto de Desenvolvimento Familiar Chieko Nishimura, onde os participantes da AAP apresentaram seus produtos para que fossem avaliados. Nesta etapa, pôde-se perceber que a produção dos artesãos não demonstrava uma identidade local, sendo grande parte apenas uma reprodução de peças encontradas na internet ou em outras fontes de busca. Isso, provavelmente, se deve pela recente fundação da associação.

O Labsol, então, baseando-se no capítulo "Identidade e diversidade" do livro Design + Artesanato - O caminho brasileiro (BORGES, 2011), em que a produção artística e artesanal prescinde de pressupostos como a capacidade de expressar a identidade relacionada aos artesãos e artistas, ao lado das concepções de Bonfim (1999), que implicam que bens e valores produzem a cultura de uma sociedade através de suas coordenadas cronológicas e cosmopolitas, resolveu propor uma mudança no método de desenvolvimento dos produtos da AAP.

Figura 1 - Bolsa feita a partir de resíduos de jeans. Produto original da Associação de Artesãos de Pompéia.

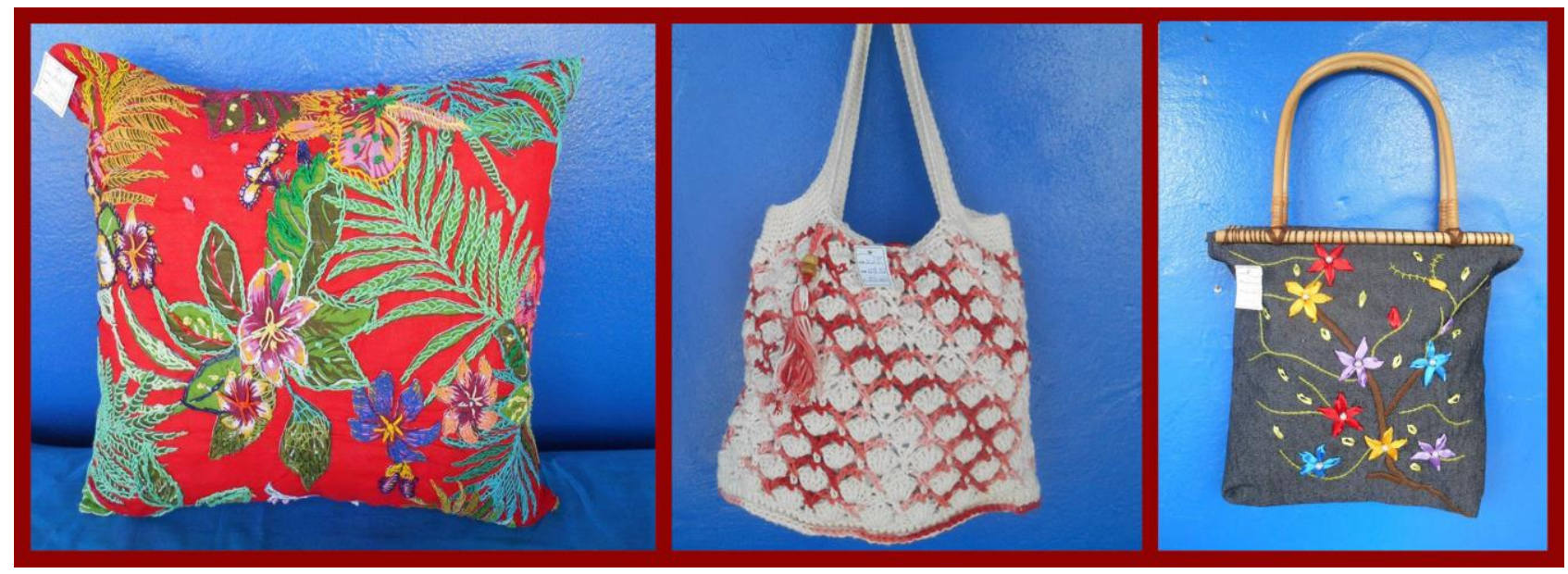

Fonte: Página do Facebook da AAP. Disponível em: Associação dos Artesãos de Pompéia -APP

A proposta de mudança consistia no aproveitamento de matéria prima ou de características locais como base do desenvolvimento dos produtos. Dessa maneira, o trabalho é legitimado como parte integrante da cultura local e não uma reprodução de técnicas alheias. Dentro da concepção de Borges (2011), isso diferencia o artesanato brasileiro, recheado de riquezas e potencialidades, da produção meramente assistencialista.

A AAP, no entanto, não é caso em absoluto de haver falta de valor cultural em suas produções. Cabe citar que produtos que não foram apresentados no dia da visita, como os bonecos de palha de milho, representam uma conquista de sua identidade. Além disso, a qualidade de acabamento das peças apresentadas mostrou grande capacidade técnica vinda dos artesãos e a potencialidade para o desenvolvimento da Associação, construindo uma ação coletiva. Além disso, outro ponto que pôde ser explorado pelo projeto de extensão em relação à produção da AAP foi a presença do uso de lona em alguns seus produtos, o que, somando a quantidade de resíduos presentes na Jacto Inc., definiu-se a proposta de envolvimento: os membros do Labsol, considerando a capacidade técnica da AAP, iriam conceber produtos feitos de Iona de vinil, gerando, como afirma Silveira (2011), uma linha de peças por artesanato urbano. 


\subsection{Elaboração de Produtos}

Após a visita, a Jacto Inc. entregou uma quantidade de lona de vinil que pudesse ser utilizada para a produção de modelos e protótipos. Através do método de desenvolvimento quantitativo de Baxter (2011), os membros do projeto de extensão começaram a elaborar diversas propostas, uma vez que, essa metodologia consiste em disponibilizar o maior número de ideias, garantindo maiores chances de encontrar produtos de qualidade.

O Labsol, no entanto, não segue totalmente a metodologia de desenvolvimento de produto através do fluxograma de Baxter (2011), pois a mesma consiste em, após decisões administrativas sobre a produção, etapas de análise de similares, desenvolvimento e escolha dos melhores conceitos e configurações, prototipagem e, por fim, a produção real, enquanto cada membro do projeto de extensão atua individualmente em uma ideia sem necessariamente apresentar variações de conceituação e configuração, visando apenas conceber o máximo de protótipos viáveis para a proposta. Contudo, a etapa de análise de similares e referências é mantida.

Figura 2 - Matriz de protótipos desenvolvidos para a parceria da AAP com o Labsol

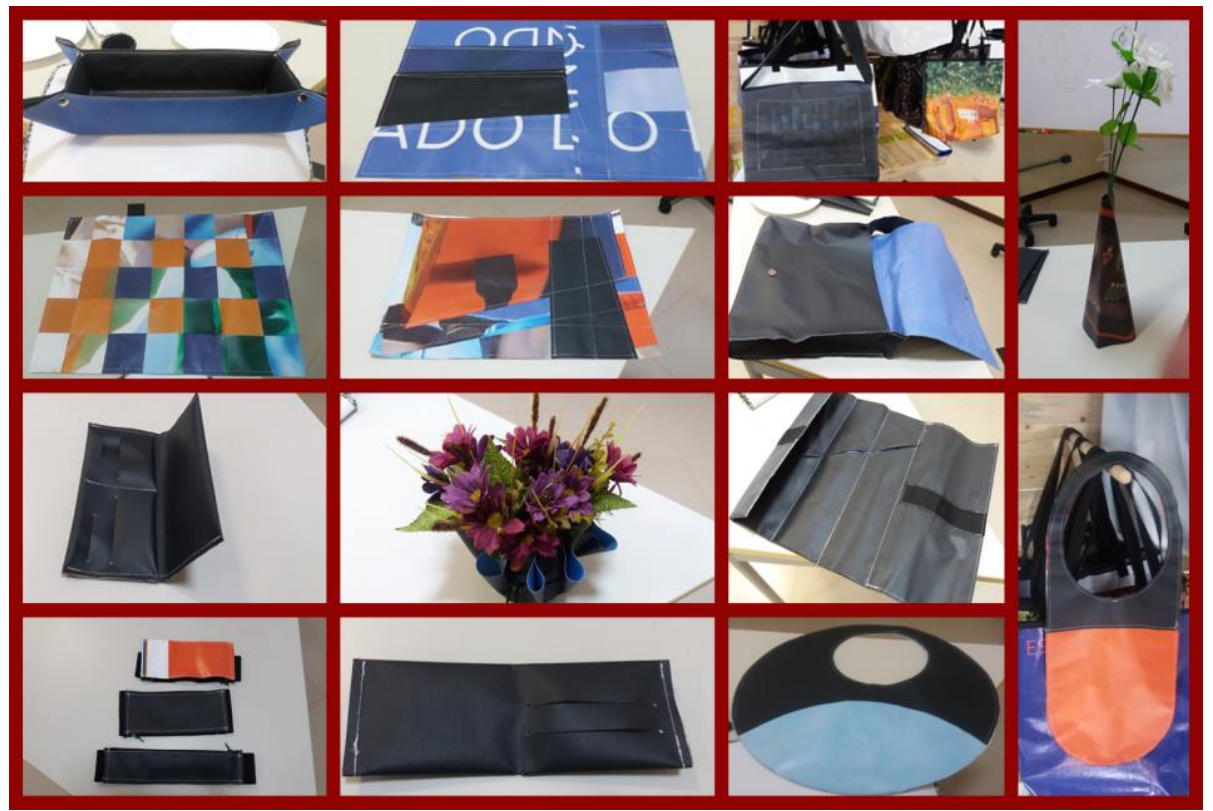

Fonte: acervo próprio

O levantamento de similares não se limitou em produtos feitos de lona, pois a ideia principal era de conceber novas configurações para artefatos gerais que chamassem a atenção dos consumidores regionais. Para tanto, produtos que pudessem ser costurados ou que usassem tecidos como material secundário foram a maior seleção, tanto pelas ferramentas disponíveis no laboratório do projeto, quanto pelas habilidades de costura e acabamento que puderam ser analisadas durante a viagem. 


\subsubsection{Cachepots de lona}

A lona de vinil oferecida para prototipagem apresentava um lado impresso, geralmente com cores variadas e o verso, acinzentado e mais liso. Para a produção de peças mais decorativas, como consenso do grupo, decidiu-se pelo uso do lado colorido por sua capacidade de gerar padrões únicos para cada aplicação. No entanto, apesar do uso da área colorida ser mais favorável para a unicidade das peças, o verso contrastava nas peças pela sua cor neutra, de maneira que reforçava a origem do material e garantia uma dualidade nos produtos. Pensando nisso, alguns protótipos deveriam apresentaram a possibilidade do consumidor final de escolher qual lado gostaria de expor e/ou de estar com as duas partes à mostra.

A ideia de conceber recipientes de lona como cobertas para vasos surgiu dessa necessidade de demonstrar os dois lados, uma vez que o verso estaria à mostra no produto final, entregando contraste. No entanto, para a estruturação da peça, ainda não havia solução.

Durante a análise de similares, os membros do grupo conseguiram encontrar vasos feitos de lona, fundamentando a ideia. Porém, a estruturação desses produtos limitava a visão do verso, uma vez que apresentavam costura e, por consequência, muita proximidade em relação à terra ou ao vaso real. No entanto, com a expansão da pesquisa de referenciais, encontrou-se uma base estrutural que poderia servir dentro do projeto: as sacolas furoshiki ${ }^{1}$.

Através de testes em modelos de tamanho real, a estruturação de furoshiki se mostrou válida, com uma única necessidade de usar uma corda para aproximar as laterais sem fechar a copa da planta posicionada no vaso, se tornando um cachepot.

Figura 3 - Cachepot de lona, preso por uma corda e estruturado através do furoshiki

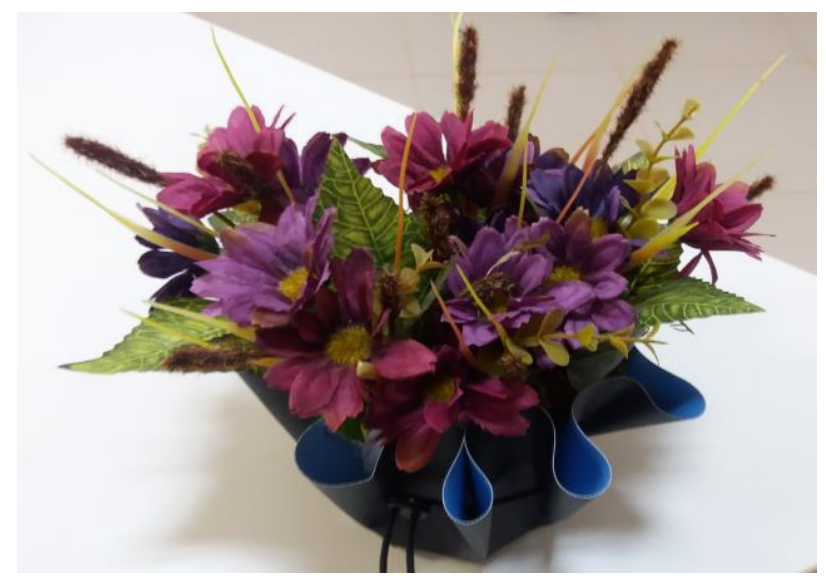

Fonte: acervo próprio

\footnotetext{
${ }^{1}$ Do japonês, Furoshiki (風呂敷), arte tradicional de embrulho com o uso de tecidos para presentes ou como acessório de moda, foi encontrada uma maneira de estruturar o tecido através de dobras, de maneira que, mesmo sem costuras, o produto fosse resistente o suficiente para carregar algum artefato.
} 


\subsubsection{Bolsa de lona cruzada}

Além das alternativas de cores e texturas garantidas pela frente/verso da lona de vinil descartada, a variação de formas gráficas geradas pela impressão também é uma característica notável do material. Isso contribuiu para alguns membros do projeto testarem diversos padrões, possibilitando a aplicação das lonas em tiras cruzadas.

À princípio o uso das tiras cruzadas que geram padrões de cores únicos foi para o desenvolvimento de jogos americanos e outros suportes (que também tiveram protótipos concebidos e enviados para a AAP), mas esse conceito ganhou outras opções, como bolsas.

As bolsas geradas pelo Labsol com essa aplicação usam lona na estrutura e nas alças, além da área central (onde estão os cruzamentos), sendo todas as tiras e peças costuradas para conseguir maior rigidez no produto.

Figura 4 - Bolsa (esquerda) e Jogo americano (direita), ambos de lona cruzada e costurada

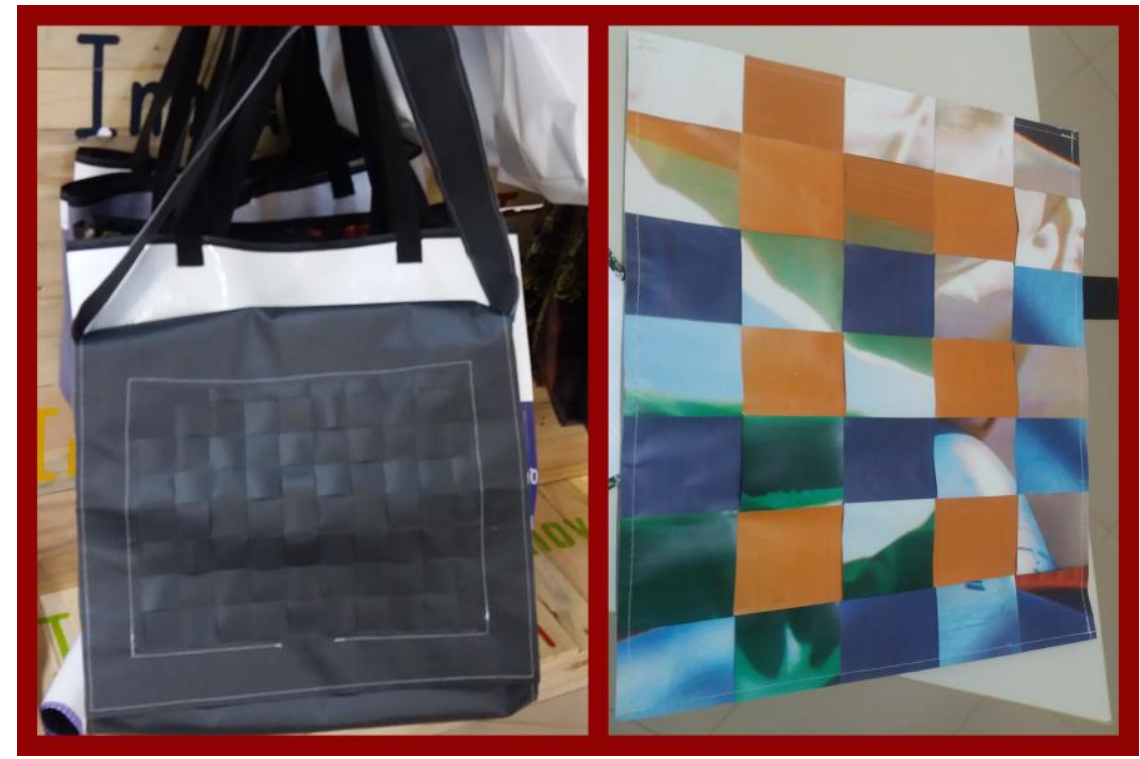

Fonte: acervo próprio

No total, a equipe do projeto de extensão conseguiu elaborar 17 protótipos voltados para utilidades gerais, tais como vasos, armazenamentos de ferramentas, carteiras, bolsas e outros. 


\section{Resultados e Discussões}

\subsection{Entrega de Protótipos}

Em agosto de 2017, o Labsol retornou à Pompéia para mostrar os produtos concebidos e para serem produzidos pela AAP. Os artesãos e representantes da Jacto Inc. apreciaram a qualidade dos protótipos desenvolvidos e receberam as devidas instruções de como reproduzi-los.

Além disso, a parceria com o Labsol contribuiu para que eventos se interessassem pela associação. A título de exemplo, o 13. Colóquio de Moda, ocorrido em outubro de 2017, convidou a AAC a participar no Bazar do evento.

\subsection{Colóquio de Moda}

O convite à AAP foi feito através do contato com a UNESP, pedindo que vendessem suas produções durante o bazar do 13. Colóquio de Moda, de maneira a contribuir com a qualidade do evento e divulgar a associação. O Labsol indicou a AAP a expor os produtos desenvolvidos durante a parceria, uma vez que esses apresentavam maior qualidade e um valor cultural do artesanato urbano. No entanto, houve uma implicação extremamente negativa durante essa indicação, onde os artesãos sentiram que seus produtos originais seriam deixados de lado e de que não apresentavam valor algum, além de que não conseguiriam produzir as novas peças à tempo. Por essa razão, exigiram que, durante o bazar, somente os produtos que não foram concebidos pela parceria fossem expostos.

Apesar do descontentamento apresentado pela AAP, os produtos gerados pela parceria também foram levados para o Bazar do evento ao lado de suas produções originais. 
Figura 5 - Bolsas de lona produzidas para o 13. Colóquio de Moda pela AAP.

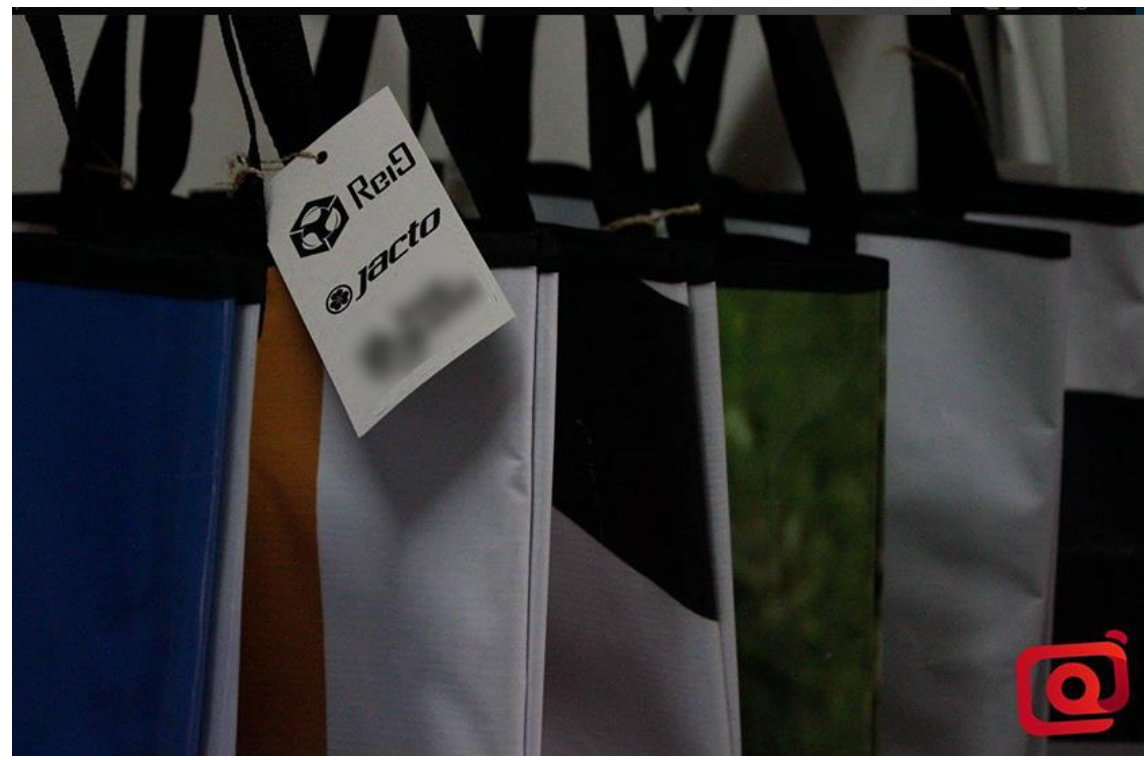

Fonte: Acervo do 13. Colóquio de Moda. Disponível em:

https://www.flickr.com/photos/152219369@N04/37851604316/in/album-72157687736751520/

\subsection{Revisão de Metodologia}

Depois dessa e outras parcerias que o projeto Labsol participou ao longo de sua existência, surgiu a necessidade de avaliar a própria metodologia, tanto em relação à produção de protótipos, quanto em abordagem à comunidade.

A parceria com a AAP demonstrou, em 2017, diversas falhas de método, principalmente pela situação apresentada durante o 13. Colóquio de Moda. No entanto, desde o início da parceria, o trabalho não constava no escopo do Labsol, pois a demanda de produção e da contribuição foi requisitada pela Jacto Inc. e não pelos artesãos, gerando uma divergência de interesses que não atendia a real necessidade da AAP.

O Labsol apresentou propostas que poderiam fazer as produções da AAP receberem maior valor cultural e, consequentemente, através da sustentabilidade, ecologia e diversos outros aspectos presentes no design, aumentar a qualidade de seus produtos. No entanto, pela falta de interação da parceria (ocorrendo apenas dois momentos de encontros, sendo o primeiro para reconhecimento e, o segundo, para entrega das peças), os artesãos da associação sentiram uma imposição, não participando efetivamente da elaboração dos produtos, evitando que pudessem projetar seus valores artísticos. Porém isso não foi percebido pelo Labsol, havendo uma divergência de visões e demonstrando o embate do acadêmico contra o conhecimento da comunidade e do design com o artesanato.

Utilizar o conhecimento apreendido na universidade exportando à comunidade afora é uma tarefa ardilosa, uma vez que o conhecimento acadêmico, tais como metodologias de projeto, 
quando é posto à prova, sempre existe a necessidade de ser adaptado. Esse caso se torna ainda mais evidente quando as metodologias são aplicadas em grupos que não receberam instruções técnicas, como é o caso de associações sem vínculo industrial.

Parte dessa dificuldade se vem pelo próprio método de ensino dos cursos, onde as disciplinas contribuem para uma visão de desenvolvimento industrial dos estudantes. Em Projetando Produtos Sociais de Silva (2009), por exemplo, o autor apresenta uma crítica à concepção de "Desenho Industrial", apontando a falta de precisão quanto ao conhecimento, consciência e envolvimento social do projetista e de sua equipe, além das estratégias e visão das empresas. São poucas as oportunidades de experimentar metodologias científicas e industriais envolvendo comunidades.

Como a parceria com a AAP se mantém, o Labsol pretende encontrar outras metodologias que consigam se aproximar mais da comunidade externa de maneira que haja maior interação dos artesãos e usuários dentro da etapa de concepção dos produtos, contribuindo na difusão de conhecimentos para ambos os lados, tais como Design Centrado no Usuário (LOWDERMILK, 2013) e Design Participativo (NYGAARD, 1973).

\section{Referências}

BAXTER, Mike. Projeto de produto - Guia prático para o design de novos produtos. 3 Ed. São Paulo: Blucher, 2011.

BREZET, H. VAN HEMEL, C. BÖTTCHER, H. CLARKE, R. Ecodesign: a promising approach to sustainable production and consumption. UNEP, 1997.

Bomfim, A. G. Coordenadas cronológicas e cosmológicas como espaço das transformações formais. In: Formas de design: por uma metodologia interdisciplinar. Rio de Janeiro: 2AB, 1999. $137-155$.

BORGES, Adélia. Design + Artesanato - O caminho brasileiro. São Paulo: Editora Terceiro Nome, 2011.

GOYA, C. R.; ANDRADE, A. B. P.; DOMICIANO, C. L. C.; ROSSI, D. C.; MEDOLA; F. O.; HENRIQUES, F, SILVA, J. P. C., PASCHOARELLI, L. C.; MOURA, M.; RODRIGUES, O. V.; BIGAL, S. M.; BARATA, T. Carnaval, Cultura Popular e Design - Uma Experiência de Extensão Universitária em Design In: Ensaios em Design - Práticas Interdisciplinares. 1 ed. Bauru: Canal 6 Editora, 2014, p. 136-156.

INSTITUTO DE DESENVOLVIMENTO FAMILIAR, C.N. Quem Somos. Disponível em: <https://www.idf.org.br/>. Acesso em 21 de março de 2018.

JACTO INC. Welcome to Jacto. Disponível em: <https://www.jacto.com/>. Acesso em 21 de março de 2018. 
LOWDERMILK, Travis. Design Centrado no Usuário. São Paulo: Editora Novatec, 2013.

MANZINI, Ezio; VEZZOLI, Carlo, trad. CARVALHO, Astrid de. O Desenvolvimento de Produtos Sustentáveis: os requisitos ambientais dos produtos industriais. São Paulo: EDUSP, 2002.

NYGAARD, K., BERGO, O.T.: Planlegging, styring og databehandling. In: Grunnbok for fagbevegelsen, Planning, Control and Data Processing. Basic Reader for Trade Unions, 2nd edn. Tiden Norsk Forlag, Oslo (1973).

SILVA, D. E. N. Projetando produtos sociais: a descrição de uma metodologia de trabalho no componente curricular projetual em cursos de design. III Simpósio Nacional de Tecnologia e Sociedade. 2009.

SILVEIRA, E.; CUNHA, J. 0 artesanato urbano e sua relação com 0 artesanato tradicional e o design. VI Congresso Internacional de Pesquisa em Design. 2011.

SINGER, Paul. Introdução à Economia Solidária. São Paulo: Fundação Perseu Abramo, 2002. 